\title{
Shielding of Turbomachinery Broadband Noise from a Hybrid Wing Body Aircraft Configuration
}

\author{
Florence V. Hutcheson*, Thomas F. Brooks", Casey L. Burley ${ }^{*}$, Christopher J. Bahr \\ NASA Langley Research Center, Hampton VA \\ Daniel J. Stead ${ }^{* *}$ \\ Northrop Grumman, Hampton VA \\ D. Stuart Pope ${ }^{* * *}$ \\ Analytical Services and Materials, Hampton VA
}

The results of an experimental study on the effects of engine placement and vertical tail configuration on shielding of exhaust broadband noise radiation are presented. This study is part of the high fidelity aeroacoustic test of a 5.8\% scale Hybrid Wing Body (HWB) aircraft configuration performed in the 14- by 22-Foot Subsonic Tunnel at NASA Langley Research Center. Broadband Engine Noise Simulators (BENS) were used to determine insertion loss due to shielding by the HWB airframe of the broadband component of turbomachinery noise for different airframe configurations and flight conditions. Acoustics data were obtained from flyover and sideline microphones traversed to predefined streamwise stations. Noise measurements performed for different engine locations clearly show the noise benefit associated with positioning the engine nacelles further upstream on the HWB centerbody. Positioning the engine exhaust 2.5 nozzle diameters upstream (compared to 0.5 nozzle diameters downstream) of the HWB trailing edge was found of particular benefit in this study. Analysis of the shielding performance obtained with and without tunnel flow show that the effectiveness of the fuselage shielding of the exhaust noise, although still significant, is greatly reduced by the presence of the free stream flow compared to static conditions. This loss of shielding is due to the turbulence in the model near-wake/boundary layer flow. A comparison of shielding obtained with alternate vertical tail configurations shows limited differences in level; nevertheless, overall trends regarding the effect of cant angle and vertical location are revealed. Finally, it is shown that the vertical tails provide a clear shielding benefit towards the sideline while causing a slight increase in noise below the aircraft.

\section{Introduction}

NASA has a goal to define a technological foundation for the development of new generations of quieter and more efficient airliners ${ }^{1}$. One objective is to introduce new aircraft concepts by 2020 that would enable the development of aircraft configurations that are 42 cumulative EPNdB quieter relative to Stage 4 of the aircraft noise certification level defined by the Federal Aviation Regulations (FAR 36) for a large twin aisle aircraft. To this end, a Hybrid

*Senior Research Engineer, Aeroacoustics Branch, Senior Member AIAA

\# Senior Research Scientist, Aeroacoustics Branch, Fellow AIAA

${ }^{\wedge}$ Research Engineer, Aeroacoustics Branch, Member AIAA

*** Senior Engineer 
Wing Body (HWB) aircraft configuration (designated as N2A-EXTE) was designed. The development of the N2A-EXTE was performed by a team led by Boeing under a NASA NRA ${ }^{2}$. This HWB configuration has twin high bypass ratio turbofan engines mounted above the airframe. The airplane forebody is intended to shield the fan and turbomachinery noise radiating forward from the engine inlet, while aft turbomachinery and jet noise shielding would be found by moving the engine nacelles forward of the trailing edge. Twin vertical tails (or "verticals") would be used to shield to the side of the flight path. For quieter control surfaces, slats are replaced by drooped leading edges, and flaps are replaced by trailing edge elevons.

A high fidelity aeroacoustic test of this HWB aircraft configuration was performed in the 14by 22-Foot Subsonic Tunnel at NASA Langley Research Center $^{3-5}$. This was an extensive effort which involved the fabrication of the high fidelity model and required substantial NASA infrastructure and measurement capability investments ${ }^{6}$. Multi-positional jet engines and broadband engine noise simulators were also developed by NASA for shielding testing. Aspects of the test, reported in this and companion papers ${ }^{5-12}$, are the examination of noise shielding parameters (such as engine location, vertical and nozzle configurations) with regard to noise emission, and the determination of the noise spectra, levels, and directivity of the base vehicle and its components. Finally, the results from this test are used to support the noise assessment ${ }^{7}$ of this HWB design and to validate the "low noise" characteristics of this aircraft concept.

The N2A-EXTE HWB aeroacoustics test was conducted in three parts. In the first part (focus of the present paper), the effects of engine placement and vertical configuration on the shielding of the broadband component of turbomachinery noise emanating from the exhaust of the nacelles were examined. The results of this study are presented herein. This first test segment also included the examination of the effects of flight conditions (approach and take off) on shielding of the exhaust noise, and of wing leading edge configuration (drooped or un-drooped) on shielding of inlet noise emission. These test results, although not included in this paper, were used to support the N2A-EXTE noise assessment reported in reference 8. The second and third parts of the test focused on airframe noise and jet noise shielding, respectively. Results from the jet noise shielding study are presented in reference 7.

The set-up and hardware used to perform the turbomachinery broadband-noise shielding segment of the N2A-EXTE HWB aeroacoustic test is described below, followed in section 3 by a description of the methodology used to analyze the acquired data. The results on the effects of engine placement and vertical configuration on shielding are discussed in section 4 .

\section{Test description}

As mentioned above, the N2A-EXTE HWB aeroacoustic test was conducted in the 14- by 22Foot Subsonic Tunnel at NASA Langley Research Center. A picture of the test set-up is shown in Figure 1.

The wind tunnel test section was configured for acoustic testing, with side walls removed and ceiling raised above the flow shear layer. The test section floor was designed to provide a streamlined surface for the wind tunnel flow while maintaining good acoustic absorption. Surfaces away from the tunnel flow were covered with acoustic treatment. A full-span wind tunnel model of the N2A-EXTE HWB was positioned inverted in the test section. An overheadtraversing microphone phased array, as well as overhead- and sideline-traversing microphones were used to perform the acoustic measurements. The overhead- and sideline-traversing microphones consisted of twenty nine 1/8-inch pressure field microphones distributed around the test section. These microphones were used to obtain hemispherical characterizations of noise directivity for the different model configurations tested. They were spaced nominally at $7.5^{\circ}$ increments about the center of the test model and were traversed together to predefined streamwise stations. 


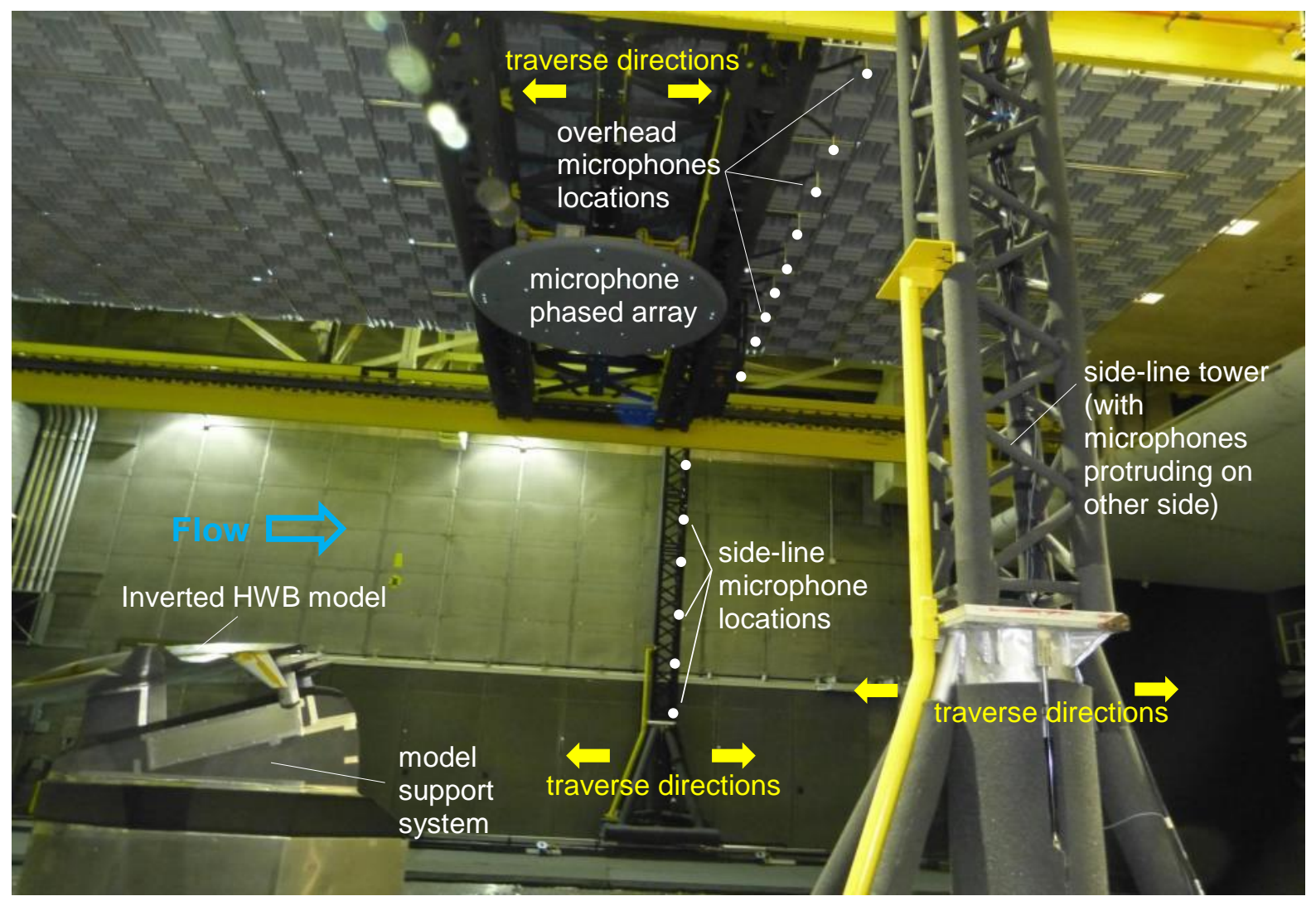

Figure 1. Test set-up inside the open test section of the Langley 14- by 22-ft tunnel.

\subsection{Test model}

The wind tunnel model was fabricated to $5.8 \%$ (12.35 foot span) of full scale. The test model scale, which was determined by the wind tunnel size and microphone frequency limitations, allowed for acoustic measurements to be performed over the full-scale equivalent range of $230 \mathrm{~Hz}$ to $4.1 \mathrm{kHz}$ (nominally $4 \mathrm{kHz}$ to $70 \mathrm{kHz}$, model-scale) that is critical to aircraft noise assessment. The test model (depicted in Figure 2) had a modular design. It consisted of a fixed blended centerbody/wing to which various components such as control surfaces and landing gears were attached. The control surface components included a drooped and a stowed leading edge to model high lift and "clean" wing configurations, twelve

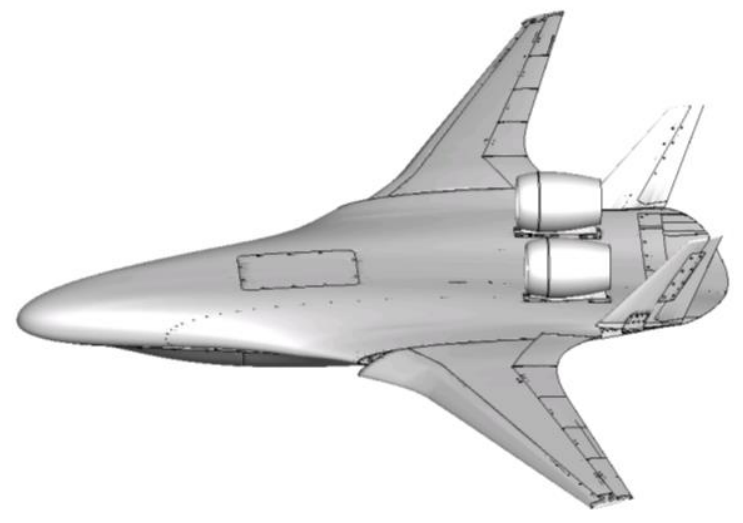

Figure 2. N2A-EXTE HWB, full-span, wind tunnel test model (shown with a drooped leading edge, and verticals and engine nacelles in their baseline configuration). elevons that were deflected along the wing trailing edge to match specific flight conditions, and twin verticals of two different sizes and cant (dihedral) angles with forward and aft fuselage positions for the engine noise shielding study. 
One pair of the verticals had manually deflectable rudders. The high fidelity of the geometric details (that can affect noise scattering) on the trailing edges and control surfaces were also emphasized during manufacturing.

\subsection{Broadband Engine Noise Simulators}

Broadband Engine Noise Simulators (BENS) were used to determine insertion loss due to shielding by the N2A-EXTE HWB airframe of the broadband component of turbomachinery noise. The broadband noise was generated by a series of opposing jet-impingement devices in the open interior of specially designed engine nacelles. A detailed depiction of the BENS is shown in Figure 3. Each BENS nacelle had a simplified core element relative to an actual engine (see inset) and three sets of impinging air jets, each supplied with 105 psig pressurized air. The inlet and exhaust of each BENS were instrumented with unsteady surface pressure sensors to monitor the noise output from the BENS assembly. Prior to testing, linearity between far field microphones and the BENS pressure sensor signals was verified. Hence, any changes in the BENS noise output due to potential variations in the supplied air pressure during testing were recorded by the pressure sensors, and noise levels measured by the test section microphones were adjusted accordingly in post-test analysis.

For the test cases reported in this paper, the nacelles' inlet was closed with an aerodynamically shaped cap (as shown in Figure 4) to only allow noise radiation from the outlet.

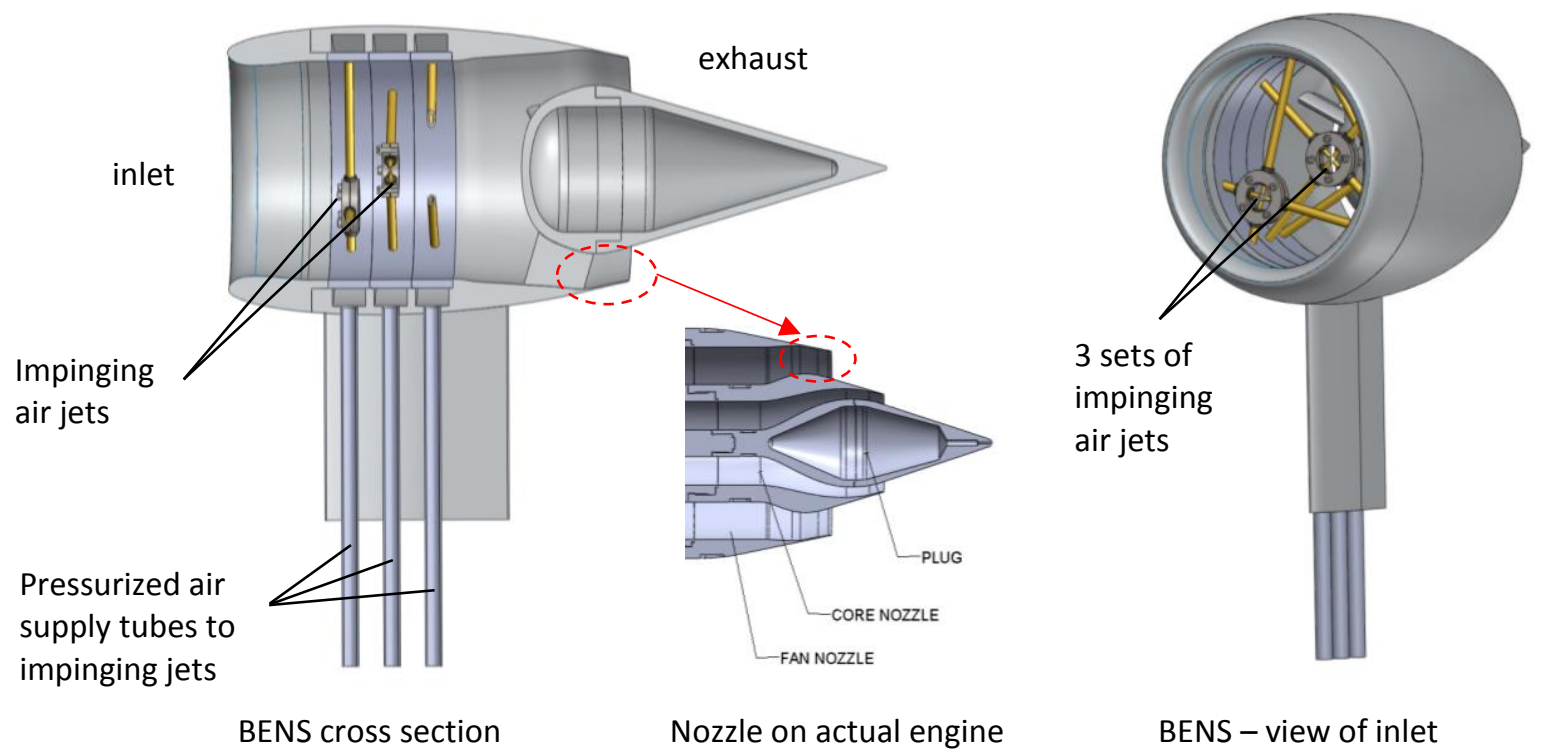

Figure 3. Broadband Engine Noise Simulator (BENS). 


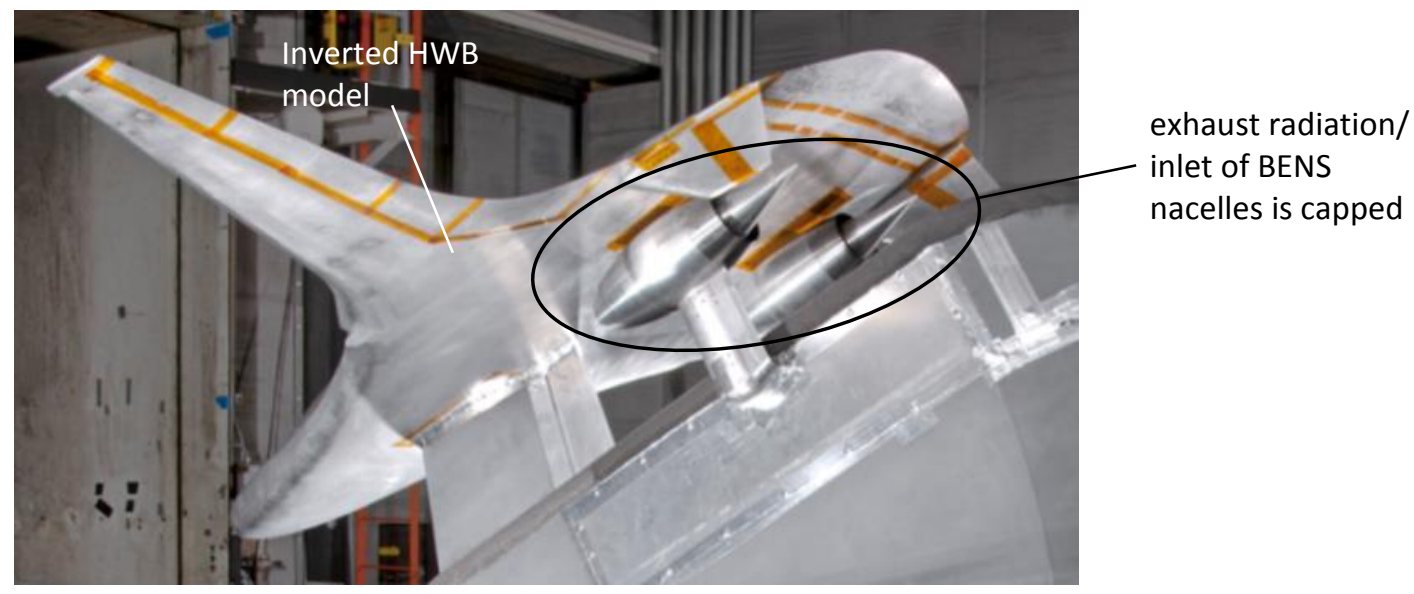

Figure 4. BENS engine nacelles in exhaust radiation configuration. (Nacelles shown in their baseline position with respect to the HWB airframe).

\section{Data acquisition and analysis methodology}

The measurements obtained from the overhead- and sideline-traversing microphones are used in the present analysis to map the directivity of the BENS noise radiation, at different streamwise locations, for each of the model configurations tested. These data are used to quantify the change in far-field Sound Pressure Level (SPL) due to shielding of the BENS noise radiation by the model airframe.

Noise field and shielding levels calculation:

To minimize potential (and unwanted) near-field effects due to the relative proximity of the overhead- and sideline-traversing microphones compared to the distance between the two BENS nacelles, the noise field produced by the Starboard-side BENS (S-BENS) and the Port-side BENS (P-BENS) were acquired separately. The noise resulting from both nacelles is subsequently obtained by adding (in the far-field and on a pressure-squared basis) the acoustic field generated by the S-BENS and P-BENS, respectively. This is permissible as the S-BENS and P-BENS noise sources are random signals and are statistically uncorrelated with each other. Note that, due to test model symmetry, the acoustic pressure field generated by the P-BENS is a reflected image (about the model center plane) of the acoustic field generated by the S-BENS. The symmetry of the acoustic field was verified by acquiring data from the P-BENS unit for a subset of test cases. Some discrepancies (attributed to asymmetries in some of the wind tunnel structures surrounding the test section) were observed but did not appear to impact shielding results. Thus, the results presented in this paper were obtained from the measurements of S-BENS noise radiation alone. The approach used to obtain the noise field from the dual engine nacelles is summarized in Figure 5 .

Once the noise field from the dual engine nacelles is obtained, the difference in SPL due to shielding by the HWB airframe of the inlet or exhaust noise radiation is determined by subtracting the SPL obtained when the engine noise is unshielded from that obtained when the engine noise is shielded. Shielding levels are expressed in $\Delta \mathrm{dB}$ and as a function of the polar and azimuthal angles $(\theta$ and $\Phi)$ defined in Figure 6.

Transient data recorders controlled by a workstation were used to simultaneously acquire the data from all microphone channels and BENS surface pressure sensors at a sampling rate of 250 
$\mathrm{kHz}$. Low pass and high pass filters set at $100 \mathrm{kHz}$ and $400 \mathrm{~Hz}$, respectively, were used to condition the outputs from each microphone and surface pressure sensor channel. Spectra were obtained from all sensor locations, for each set of data acquired. The time history signals were partitioned into non-overlapping segments of $2^{13}$ samples. Each segment was then Fourier transformed using a Hamming window. Shear layer, microphone directivity and atmospheric attenuation corrections were applied. These corrections assumed a noise source located at the center of the S-BENS exhaust for the exhaust noise radiation cases, and at the center of the S-BENS inlet for the inlet noise cases.

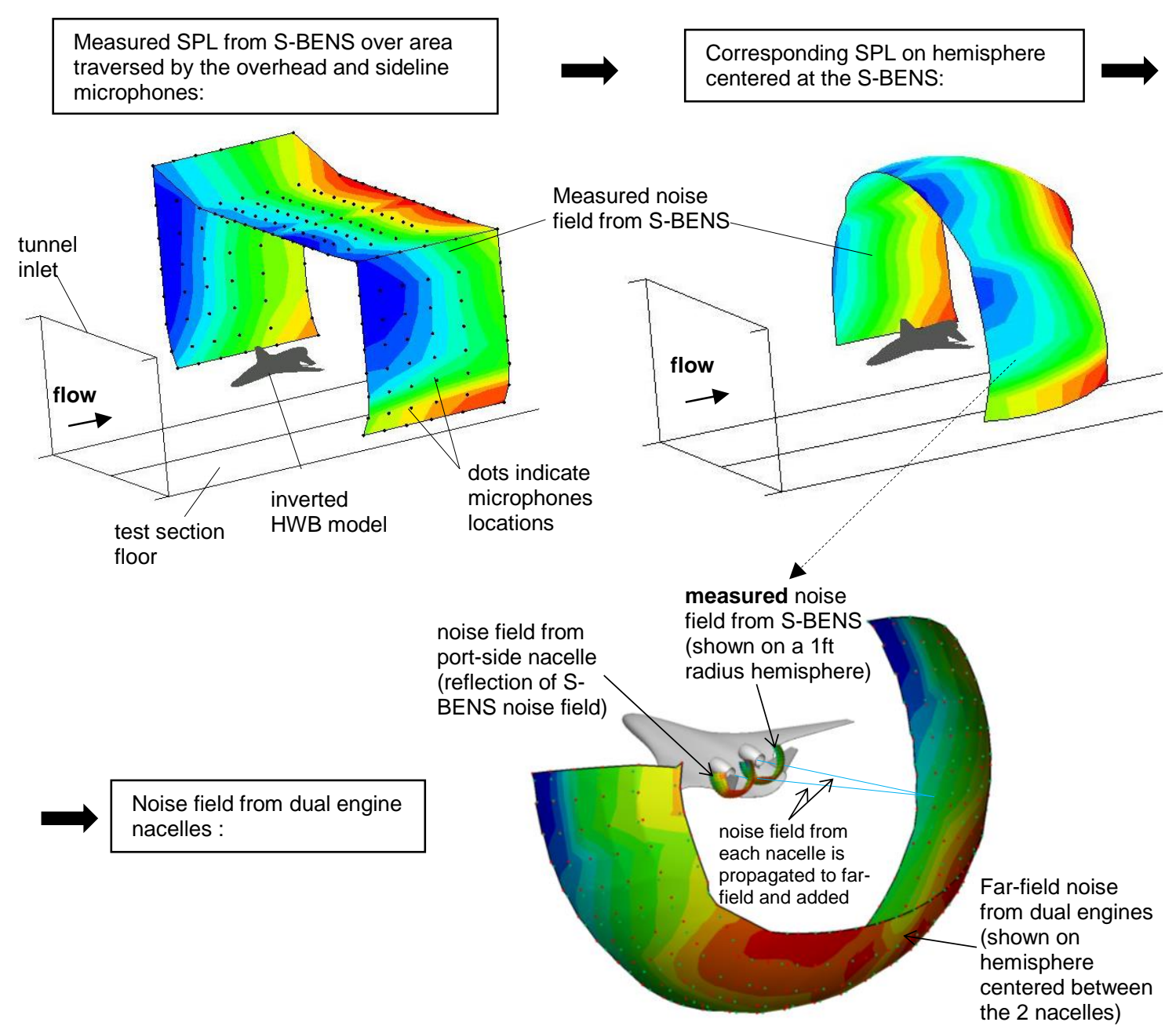

Figure 5. Dual engines noise field calculation. 


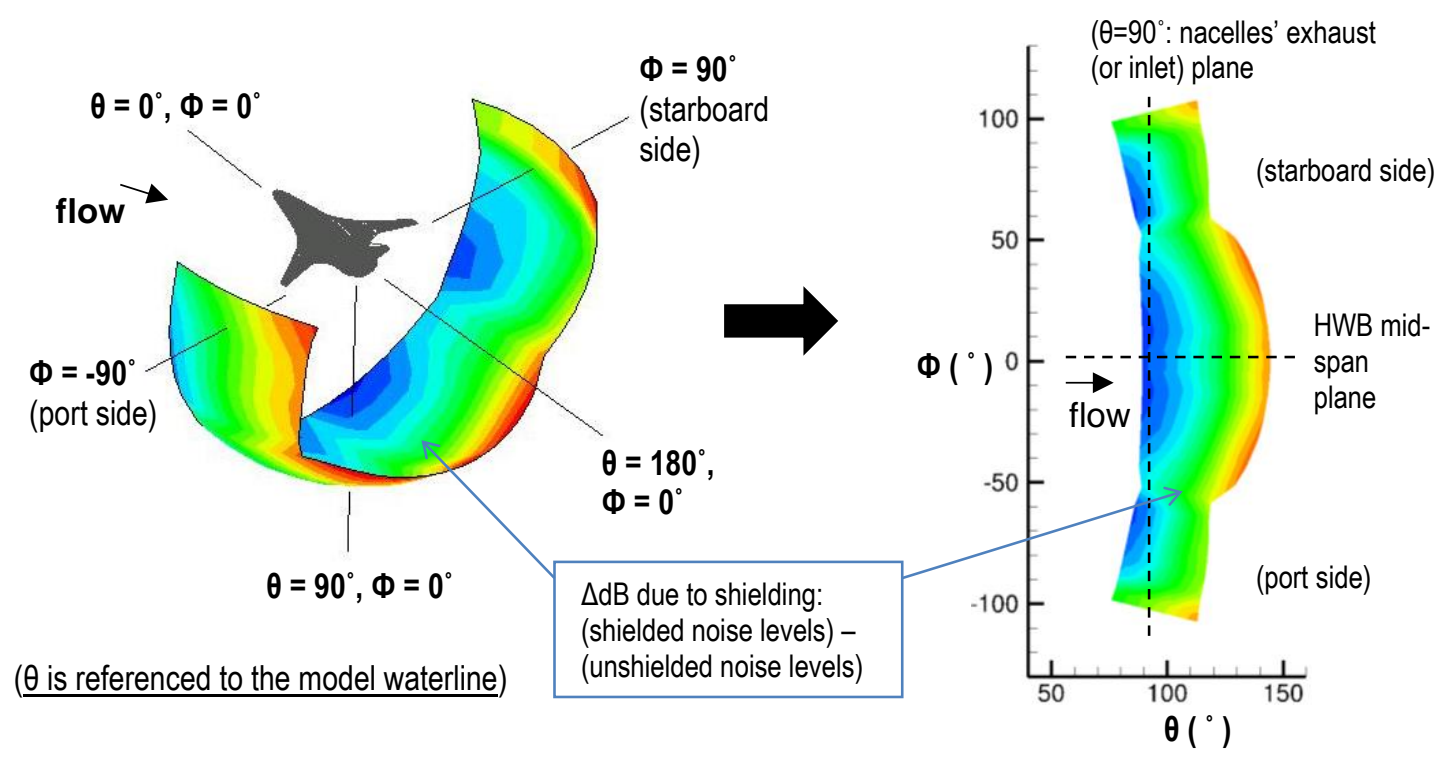

Figure 6. Coordinates system and results presentation.

\section{Results and Discussion}

The effects of engine placement and verticals configuration on the shielding of the BENS exhaust noise radiation are examined in this section. A particular focus is on the $31.5 \mathrm{kHz}$ model scale one-third octave band frequency as it corresponds to the peak frequency (about $540 \mathrm{~Hz}$ full scale) for turbomachinery noise ${ }^{8}$.

The verticals' and nacelles' position variations were performed with the HWB model airframe configured in an approach flight-simulation condition. For this condition, all elevons and rudders are un-deflected, the wing leading edge segments are drooped, the angle of attack is $13.1^{\circ}$ and the flow speed Mach number is 0.19 . Shielded and unshielded noise measurements were also obtained for the same airframe configuration without free stream flow to examine differences in shielding performance between flow and no-flow conditions.

The "unshielded" exhaust noise radiation data were obtained by positioning the BENS nozzle exhaust downstream of the airframe trailing edges, as defined in the next section.

\subsection{Effect of engine location on noise shielding}

Exhaust noise radiation data were acquired for four streamwise positions of the BENS nacelles. These positions were defined by the distance $\mathrm{X}$ (measured along the BENS axis) between the exhaust of the nacelle and the trailing edge of the model, normalized by the exhaust diameter $\mathrm{D}$. The nacelle locations tested were $\mathrm{X} / \mathrm{D}=2.5$ (baseline engine location per the N2AEXTE design), 1.5, 0 , and -0.5 (unshielded noise radiation reference case). The relative positioning of the nacelles with respect to the verticals and model trailing edge is depicted in Figure 7 for each X/D. The baseline vertical configuration (specified in section 4.2) was used in this portion of the test. 

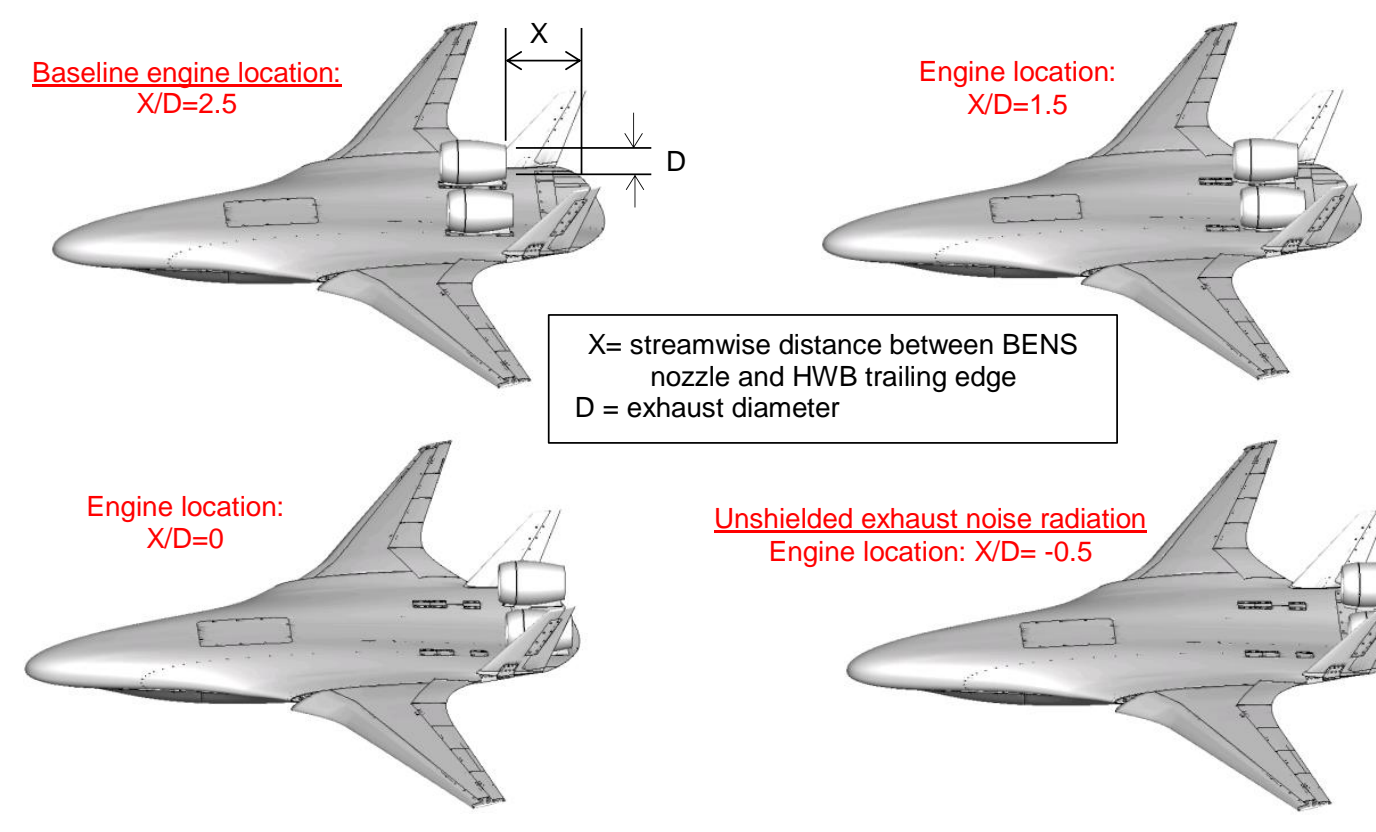

streamwise distance between
nozzle and HWB trailing edge

= exhaust diameter

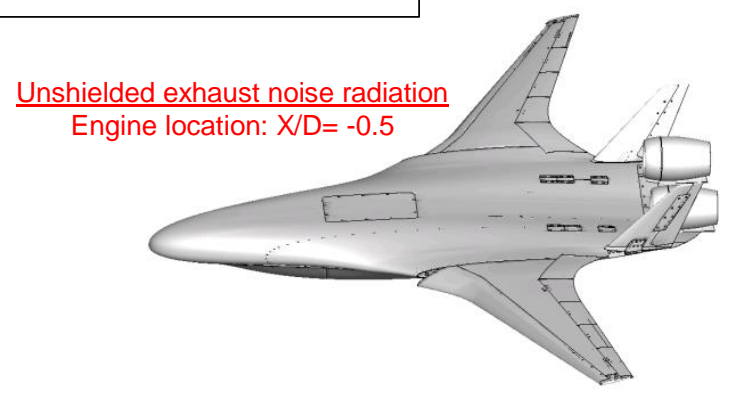

Figure 7. Engine location variation. Baseline vertical configuration; drooped LE; all elevons are un-deflected.

Shielding levels achieved for the different locations of the engine nacelles and with a free stream flow Mach number of 0.19 are shown in Figure 8 . The $\Delta \mathrm{dB}$ levels were calculated by subtracting the noise field obtained when the engine nacelles are located at $\mathrm{X} / \mathrm{D}=-0.5$ from that obtained when the nacelles are located at $\mathrm{X} / \mathrm{D}=2.5,1.5$ or 0 . Negative values mean a reduction in noise; positive values indicate a gain. It is seen from Figure 8 that the shielding effectiveness decreases as the nacelles are moved closer to the model's trailing edge from upstream. For an $\mathrm{X} / \mathrm{D}$ of 2.5 , up to $-13 \mathrm{~dB}$ in shielding are obtained, with at least $-10 \mathrm{~dB}$ over a broad range of observer angles (namely for $-50^{\circ} \leq \Phi \leq 50^{\circ}$ and $\theta \leq 125^{\circ}$ ). For $\mathrm{X} / \mathrm{D}=1.5$, the maximum shielding reduces to $-11 \mathrm{~dB}$, with -11 to $-10 \mathrm{~dB}$ in shielding achieved over a smaller range of observer angles (for $-45^{\circ} \leq \Phi \leq 45^{\circ}$ and $\theta \leq 115^{\circ}$ ). Finally, for $\mathrm{X} / \mathrm{D}=0$, the airframe does not appear to provide any significant shielding of the exhaust noise radiation. These results clearly highlight the noise shielding benefit associated with positioning the engine nacelles further upstream on the HWB centerbody. 

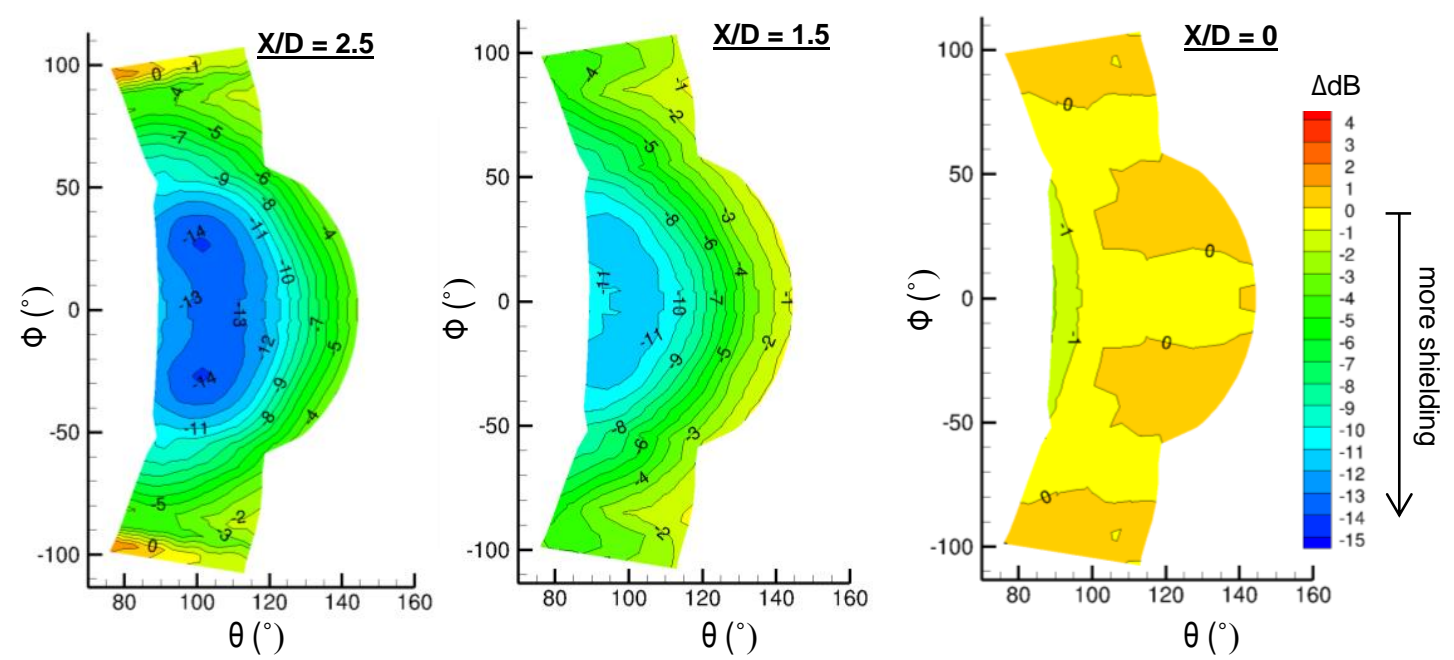

Figure 8. Shielding (i.e., $\Delta \mathrm{dB}$ due to shielding) of exhaust noise radiation; Mach=0.19; $f_{1 / 3}=31.5 \mathrm{kHz} ; \theta=90^{\circ}=$ exhaust plane of the nacelles.

Here, the effect that the free stream flow has on the shielding performance is examined for the same three engine placements. This was done by comparison to reference no-tunnel flow cases for matching model and microphone configurations. Results are presented in Figure 9. $\Delta \mathrm{dB}$ levels shown were obtained by subtracting shielding levels measured in the absence of flow from those measured with flow. Without flow and with the most upstream position $(\mathrm{X} / \mathrm{D}=2.5)$ of the nacelles, an additional 8 to $10 \mathrm{~dB}$ in shielding is obtained over the aft observer locations $(\theta \geq$ $\left.110^{\circ}\right)$, especially towards the sideline $\left(20^{\circ} \leq|\Phi| \leq 50^{\circ}\right)$. For X/D $=1.5$ (nacelle exits approximately aligned with the mid-chord of the verticals), an additional 5 to $11 \mathrm{~dB}$ in shielding is achieved on the sideline $\left(35^{\circ} \leq|\Phi| \leq 60^{\circ}\right)$ in the absence of flow, and up to $7 \mathrm{~dB}$ along the flyover line $\left(\Phi=0^{\circ}\right)$. Finally, for X/D $=0$ (exhausts positioned aft of the verticals) the increase in shielding observed without flow is mostly limited to the sideline for the most upstream observer locations $\left(\theta \leq 110^{\circ}\right)$. These results indicate that the effectiveness of the verticals (and of the aft portion of the airframe) in shielding the radiated exhaust noise is greatly reduced by the presence of the free stream flow.
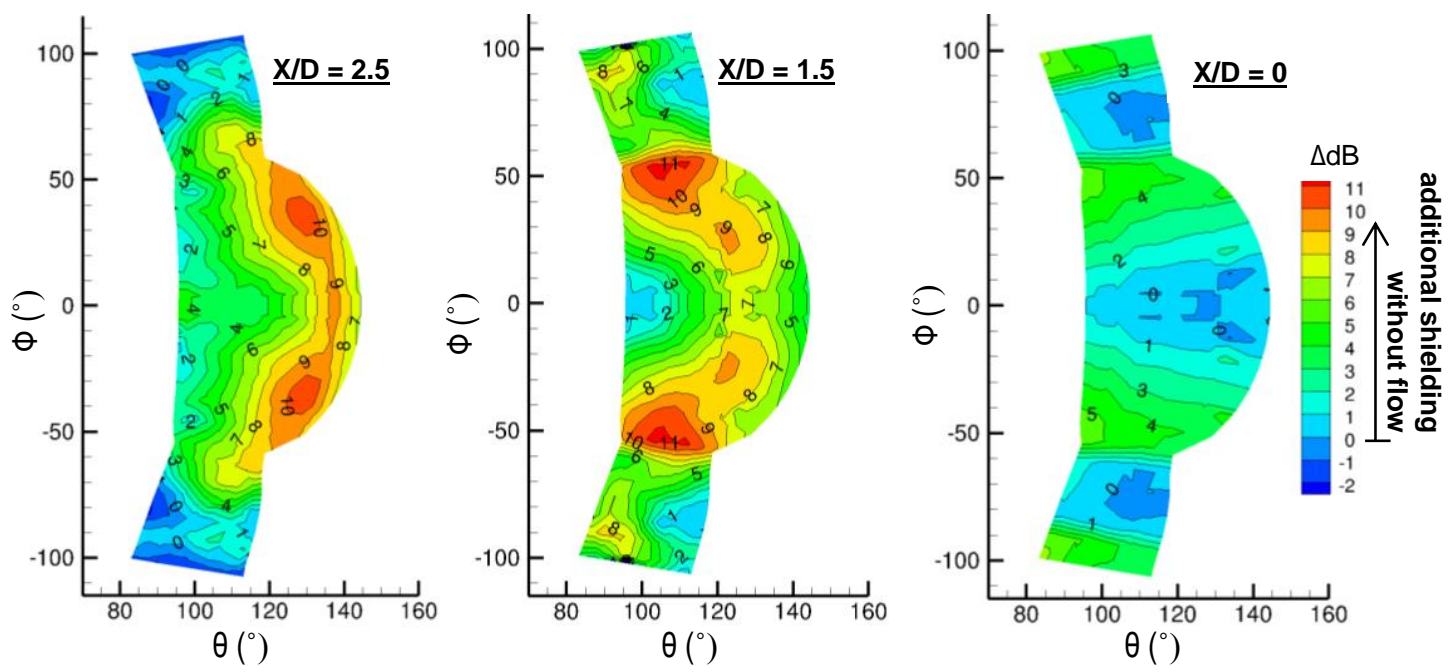

Figure 9. Effect of free stream flow on shielding. $\Delta \mathrm{dB}=$ [shielding when Mach=0.19] [shielding when Mach=0]. Positive numbers mean higher shielding levels without flow. 
Shielding effectiveness is shown in Figure 10 as a function of frequency for two observer locations. Without flow, the amount of shielding significantly increases with frequency for all three X/D positions. This is an expected classical behavior (covered by the geometrical theory of diffraction $^{13}$ and the theory of Fresnel diffraction ${ }^{14-15}$ ) for a barrier (the HWB fuselage) placed between a noise source and the observer. Below the aircraft $\left(\Phi=0^{\circ}\right)$, more shielding is achieved for larger X/D distances between the exhausts and the fuselage's trailing edge, while on the side line $\left(\Phi=50^{\circ}\right)$, shielding is also affected by the relative position of the nacelle exits with the verticals (as reflected by the greater amount of shielding achieved for $\mathrm{X} / \mathrm{D}=1.5$ than for $\mathrm{X} / \mathrm{D}=2.5$ at the noted observer location).

Figure 10 also shows that there can be significant drops in shielding effectiveness when flow is present over the airframe - compared to no-flow, especially as frequency increases. This is consistent with results of more fundamental ongoing studies of flow over barriers. It is believed that, in the same manner that turbulent shear layers in open wind tunnel test sections scatter sound on its path to a microphone ${ }^{16}$, a barrier's (HWB) trailing edge boundary layer (near wake turbulence) scatters edge-diffracted sound (shielded sound). For Mach $=0$, the diffracted (shielded) sound follows a narrow path from the edge to the observer. Spatially distributed turbulence randomly scatters the noise energy to a broader region. This would be much like a frosted glass would smear an image - making sharp shielding more difficult, and thus less effective.
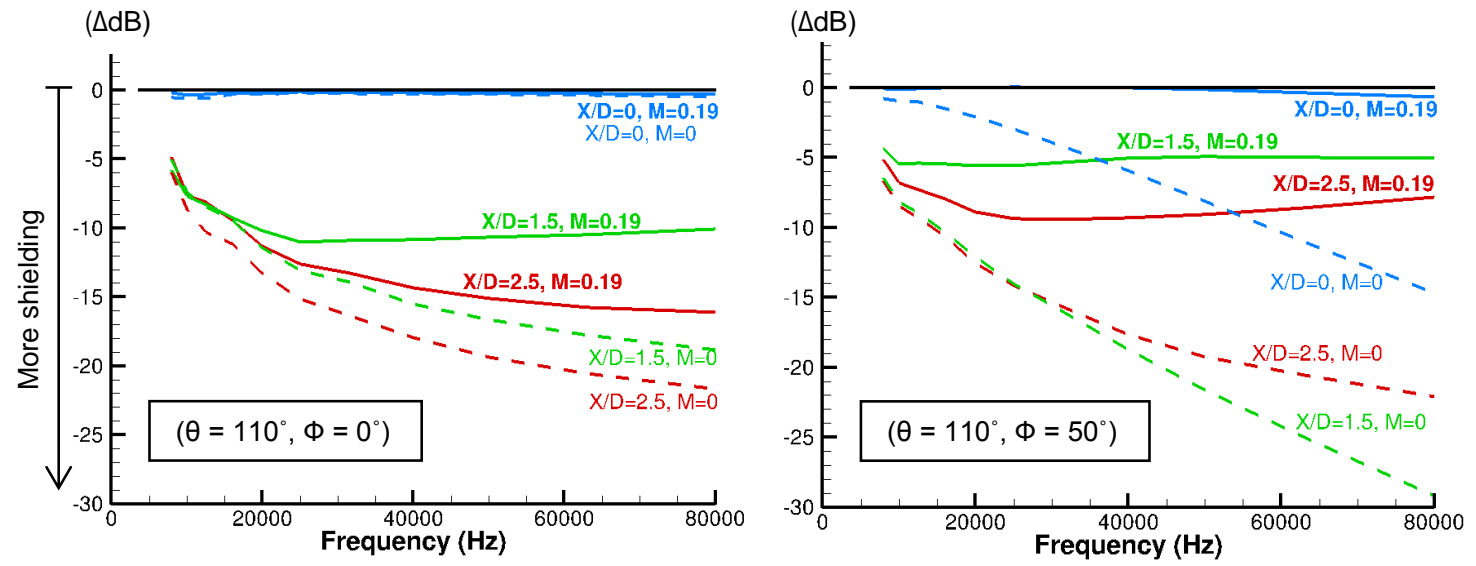

Figure 10. Shielding as a function of frequency (with and without free stream flow) for three exhaust positions.

The effects of engine placement on shielding are further illustrated in Figure 11. Measured shielding levels are shown along the fly-over and sidelines (respectively, $\Phi=0^{\circ}$ and $\Phi=50^{\circ}$ ) which are key locations in the calculation of the Effective Perceived Noise Levels (EPNL) for aircraft noise certification. As mentioned earlier, data presented in this section were obtained from test cases simulating an approach flight condition. Assuming the shielding benefits for the tonal component of turbomachinery noise to be the same as that measured for the broadband component, the effect of engine placement on the EPNL was estimated ${ }^{7}$. The results are plotted in Figure 12. It is seen that moving the engines from their unshielded location to $0,1.5$ or 2.5 nozzle 
diameters upstream of the airframe trailing edge would result in an estimated reduction of respectively, 0.4, 2.6 and 3.3 EPNdB for the approach flight condition tested.
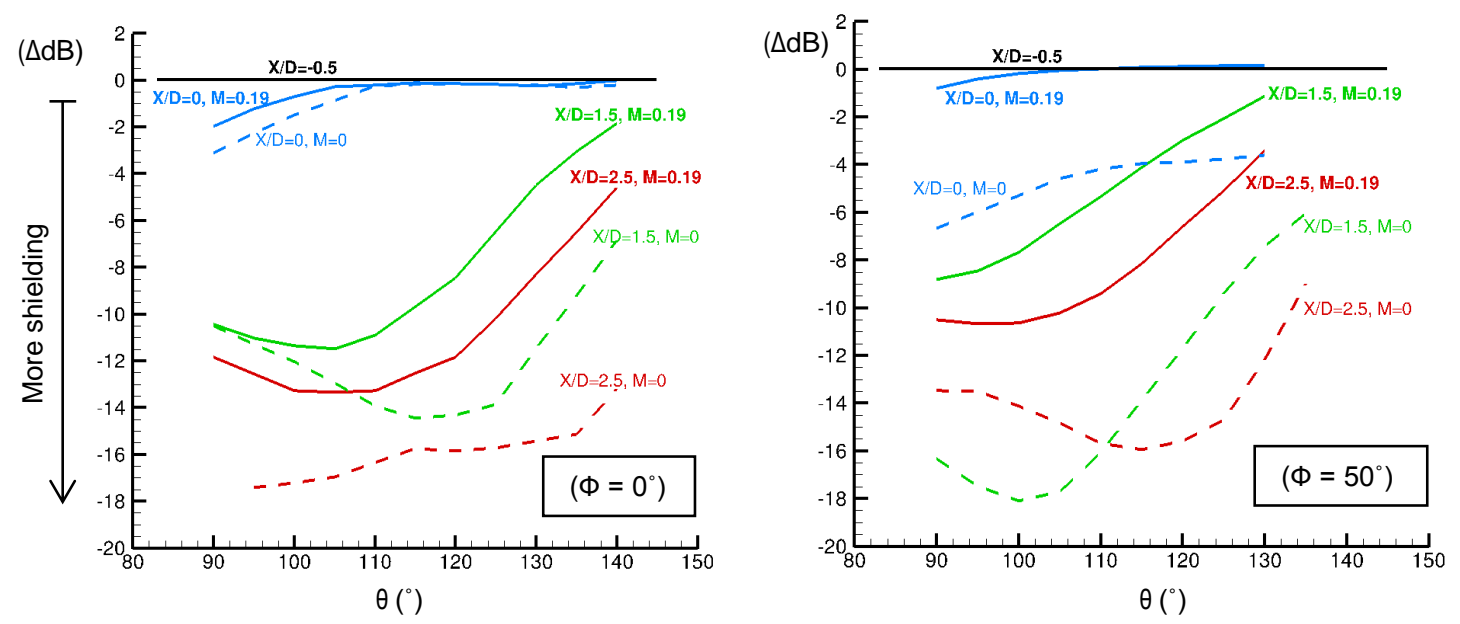

Figure 11. Shielding levels along fly-over and sidelines; $f_{1 / 3}=31.5 \mathrm{kHz}$.

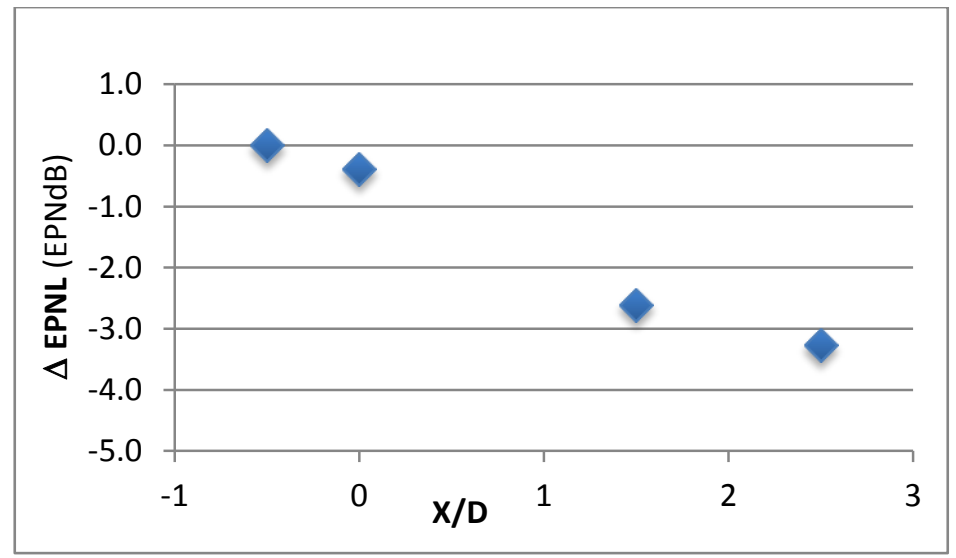

Figure 12. Estimated reduction in EPNL with engine placement for approach flight condition.

\subsection{Effect of vertical configuration on noise shielding}

The effect of alternate vertical configurations on the shielding of exhaust noise radiation is examined. The various configurations tested included two different vertical geometries, cant angles and streamwise placements (as illustrated in Figure 13). The verticals were placed at either $10^{\circ}$ or $30^{\circ}$ cant angles, and at an aft or forward position. The vertical geometries included a wide 
and a narrow chord airfoil. The baseline verticals (per the N2A-EXTE design) consisted of the narrow chord airfoils positioned in the aft location at a $10^{\circ}$ cant angle. Data were acquired with the engine nacelles in their baseline X/D location of 2.5 .
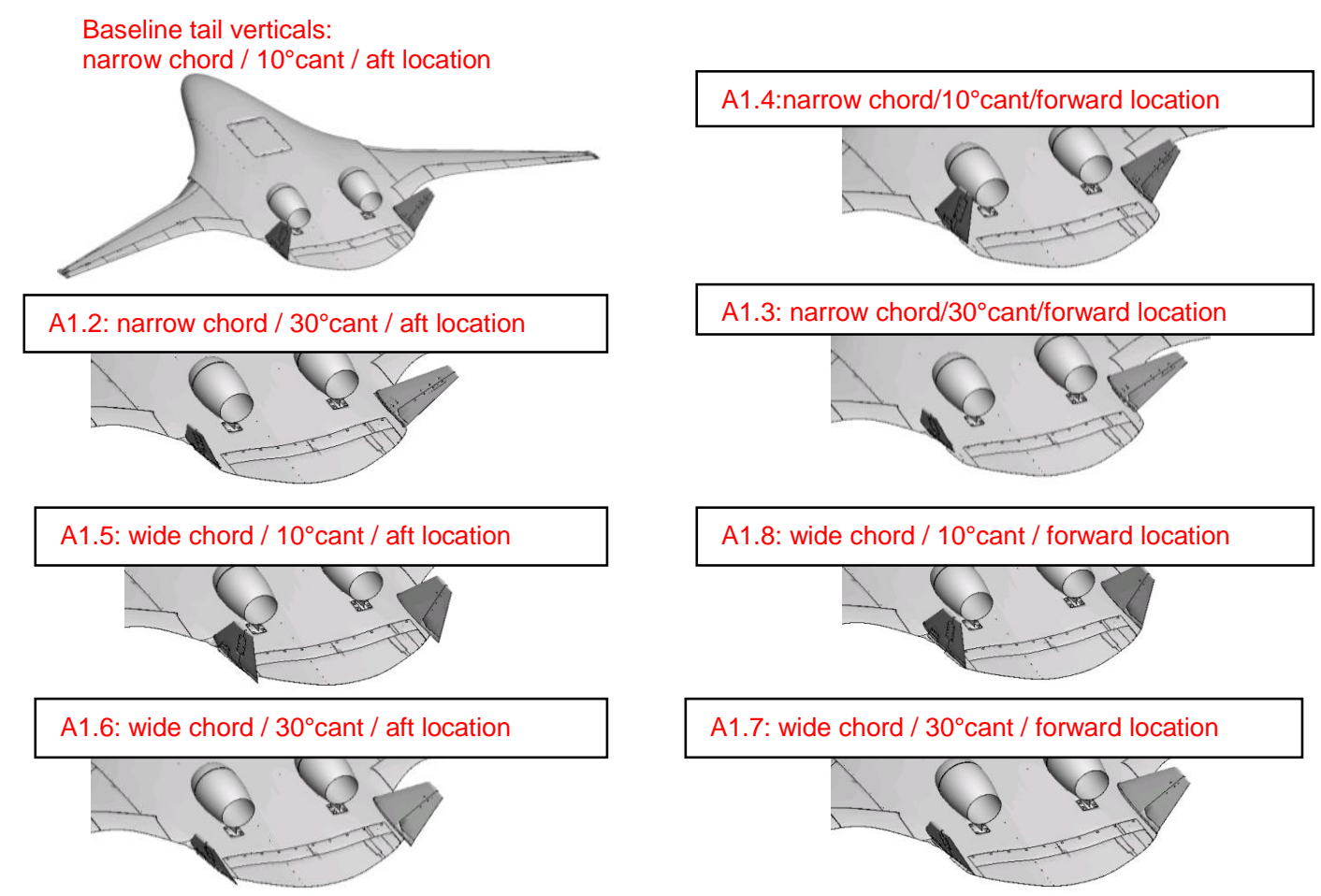

Figure 13. Vertical tail configurations tested (A1.2 through A1.7 and baseline).

Shielding levels obtained with the baseline and alternate verticals as well as with the verticals removed are compared. Results obtained for the best and worst performing verticals, as well as for the verticals-removed case are presented in Figure 14. $\Delta \mathrm{dB}$ levels shown were calculated by subtracting shielding levels obtained with the baseline verticals from those obtained with each alternate configuration. It is seen that without verticals, shielding levels along the sideline $(|\Phi| \geq$ $\left.40^{\circ}\right)$ are reduced by up to $3.5 \mathrm{~dB}$ while shielding levels below the aircraft $\left(-40^{\circ} \leq \Phi \leq 40^{\circ}\right)$ are slightly improved $(\sim-0.5 \mathrm{~dB})$. This slight improvement in shielding performance along the flyover region when the verticals are removed may indicate that a small portion of the noise shielded by the verticals is reflected or scattered towards the ground.

Changes in the vertical configuration only lead to small variations in shielding performance. Referring to Figure 14, with the best performing verticals (configuration A1.6), a slight improvement in shielding levels $(\sim-0.5 \mathrm{~dB})$ is maintained over a broad area below the airframe while up to an additional $1.5 \mathrm{~dB}$ in shielding is obtained at large sideline angles $\left(|\Phi| \geq 60^{\circ}\right)$. The A1.6 configuration also lead to a very slight reduction in shielding performance (less than $0.2 \mathrm{~dB}$ ) in some area below the airframe, as well as to a $1 \mathrm{~dB}$ reduction in shielding at the most extreme sideline angles, $|\Phi| \geq 90^{\circ}$, which would not affect the aircraft noise performance. With the worst performing tails, configuration A1.4, a reduction in shielding levels of up to $1 \mathrm{~dB}$ is observed over nearly the entire range of measurement locations, with the exception of improved shielding 
at the largest sideline angles $\left(|\Phi| \geq 80^{\circ}\right)$ which again would have little effect on the aircraft noise performance.
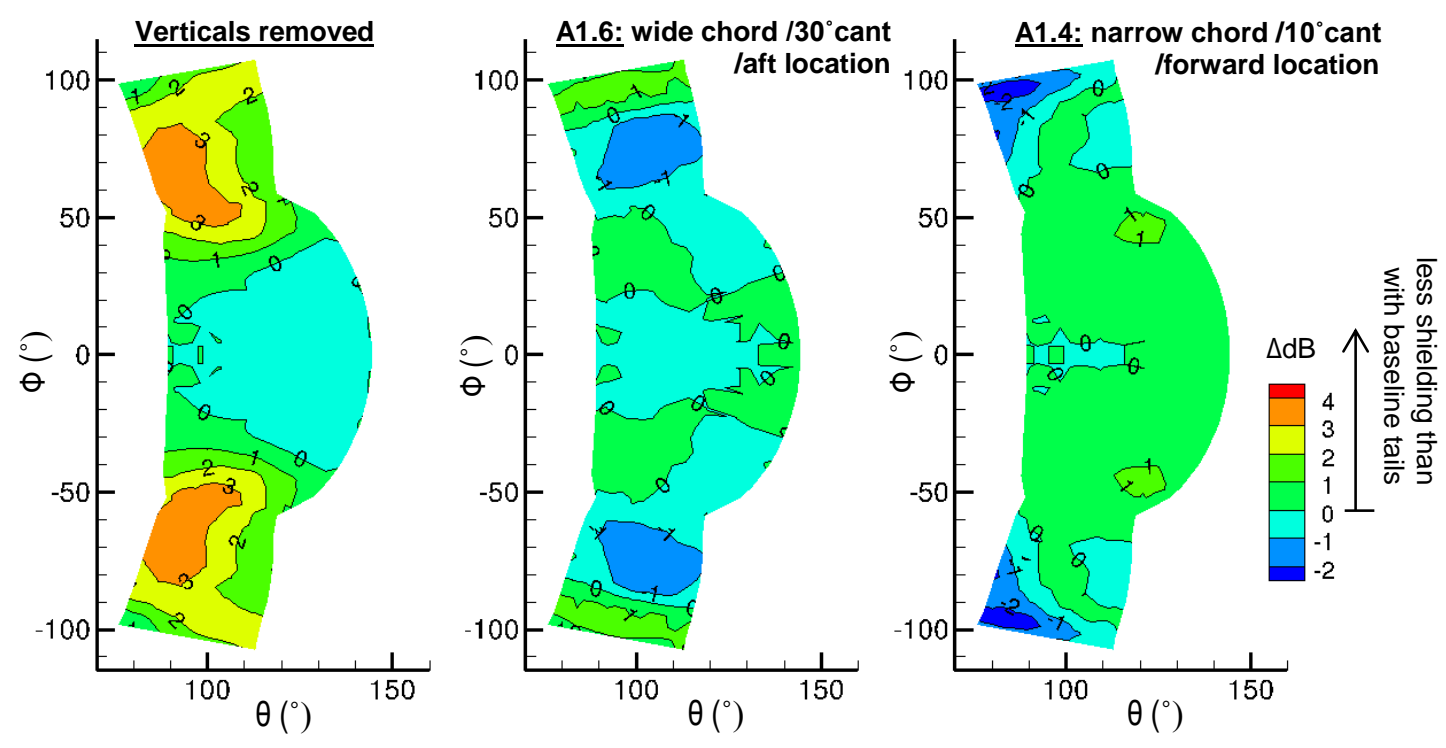

Figure 14. Shielding level variation with changes in vertical tail configuration. Exhaust noise radiation; $M a c h=0.19 ; f_{1 / 3}=31.5 \mathrm{kHz} ; \theta=90^{\circ}$ : exhaust plane of the nacelles.

Shielding levels provided by each of the alternate vertical configurations along the sideline $\left(\Phi=50^{\circ}\right)$ and along the fly-over line $\left(\Phi=0^{\circ}\right)$ are compared in Figures 15 and 16. It is seen that, except in the absence of verticals, changes in configuration have a limited effect on shielding levels. Yet, some overall trends are revealed. Aft (versus forward) located verticals appear to provide better shielding (by up to $1 \mathrm{~dB}$ ) along the fly-over and sidelines, particularly at aft observer angles $\left(\theta \geq 110^{\circ}\right)$. Furthermore, for a given vertical location (aft or forward), the $30^{\circ}$ cant angle setting appears to lead to better shielding along the sideline, as well as along the fly-over line at aft observer locations $\left(\theta \geq 115^{\circ}\right)$. Regarding the effect of the vertical geometry (narrow or wide chord) on shielding, no clear trend is seen along the fly-over line. On the sideline, for aft observer angles (i.e., $\theta \geq 110^{\circ}$ ), the wide-chord verticals seem to out-perform the other geometry when in the forward location, while the reverse is observed when the verticals are positioned in their aft location. Finally, as also previously observed in Figure 14, the verticals are seen to provide a clear shielding benefit along the sideline while causing a slight increase in noise along the fly-over line.

Note that although the A1.6 vertical configuration provided the best shielding performance over the $31.5 \mathrm{kHz}$ one-third octave band (turbomachinery noise peak frequency at model scale), the A1.2 configuration slightly out-performed the A1.6 configuration over the observer angles that are most relevant to aircraft noise assessment when considering the whole frequency range. Thus, shielding results from the A1.2 vertical configuration were used to perform the N2A-EXTE noise assessment reported in reference 8 . 


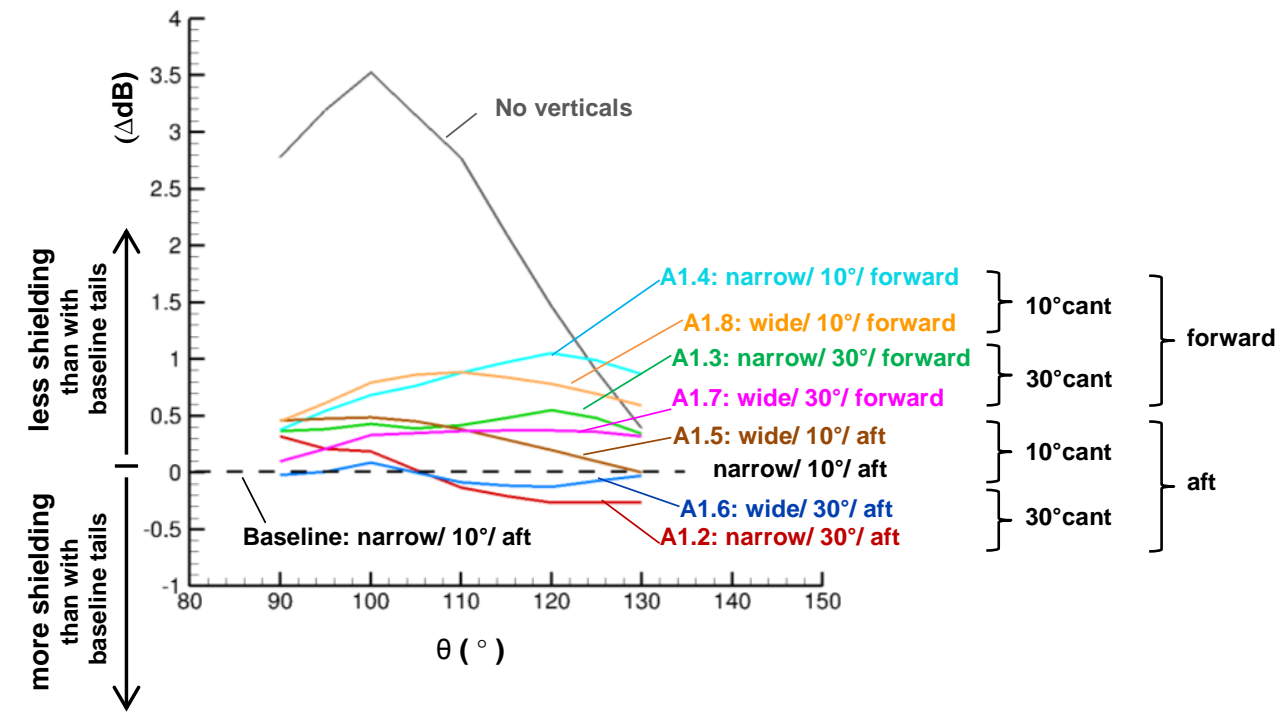

Figure 15. Comparison of shielding performance provided by the alternate vertical tail configurations at $\Phi=50^{\circ}$ (sideline). Approach flight condition; Mach $=0.19$; Angle of attack $=13.5^{\circ} ; \mathbf{f}_{1 / 3}=31.5 \mathrm{kHz}$.

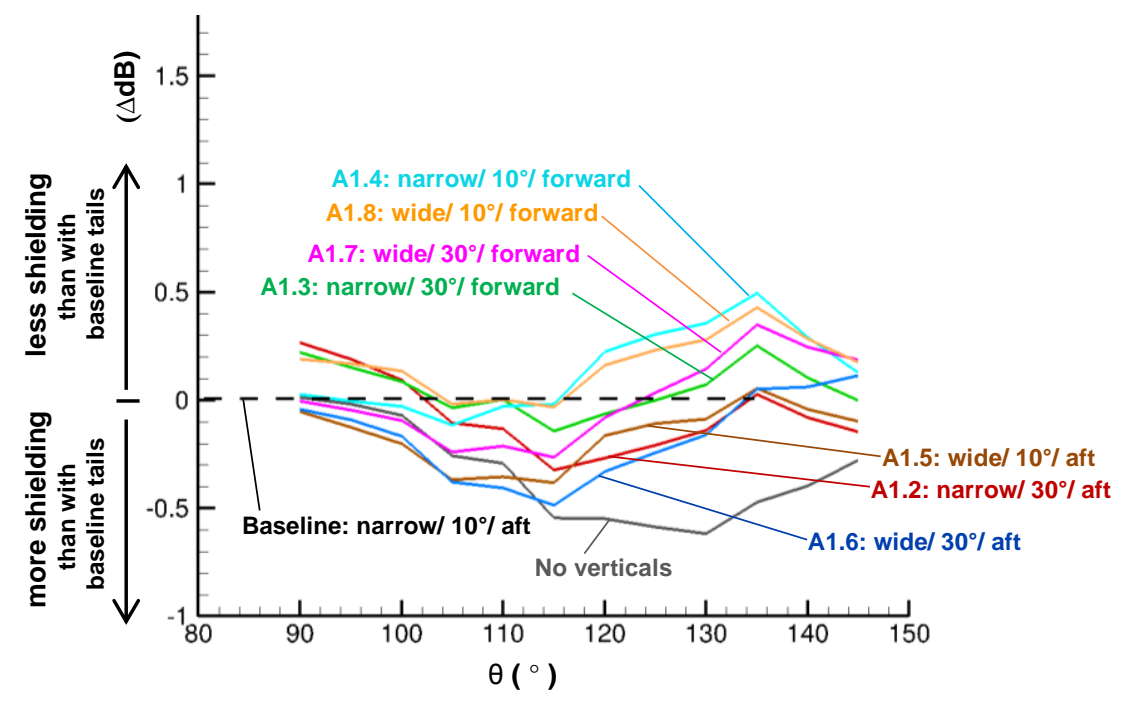

Figure 16. Same as Figure 15, except $\Phi=0^{\circ}$ (fly-over line).

\section{Summary}

The effects of engine location and vertical tail configuration on the shielding of the broadband component of turbomachinery noise for a HWB aircraft configuration were examined. This study was part of a high-fidelity aeroacoustic test conducted at NASA Langley. The broadband noise was generated by three sets of opposing jet-impingement devices located in the open interior of specially designed engine nacelles. Hemispherical characterizations of noise directivity were obtained from traversing microphones distributed around the open test section. 
Shielding levels were determined by subtracting unshielded engine noise data from the data obtained from shielded configurations.

Noise measurements performed for different positions of the engine nacelles revealed that shielding from the HWB fuselage significantly increases as the nacelles are moved upstream from the model's trailing edge. Shielding results indicated that by positioning the engine exhaust 2.5 nozzle diameters upstream of the HWB's trailing edge, up to a $13 \mathrm{~dB}$ shielding benefit is obtained (at the peak frequency for turbomachinery noise), with at least a10 $\mathrm{dB}$ benefit over a broad range of observer angles. A corresponding reduction of over $3 \mathrm{EPNdB}$ was estimated for the approach flight condition tested with this position of the engine nacelles compared to a configuration where the nacelle exits extend past the trailing edge.

Analysis of shielding measurements performed with and without free stream flow showed that the effectiveness of the verticals and of the aft portion of the airframe in shielding the radiated exhaust noise is greatly reduced by the presence of the free stream flow, especially as frequency increases. At the turbomachinery noise peak frequency, the benefits of shielding in the static condition were reduced due to flow by 1 to $11 \mathrm{~dB}$, depending on the position of the engine nacelles. It is believed that unlike in static condition, near wake turbulence from the HWB fuselage scatters the edge-diffracted sound over a broad region making shielding less effective.

Finally, shielding levels obtained with alternate vertical tail configurations as well as with the verticals removed were compared. Two different cant angles, geometry and streamwise placements were considered. While the absence of verticals led to a clear decrease in shielding towards the sideline, it also slightly improved shielding performance below the aircraft. Changes in vertical configurations were found to have a limited effect on shielding levels, yet overall trends were revealed. The verticals were most effective in shielding the exhaust noise radiation when located the furthest downstream of the nacelles, and when positioned at the largest cant angle considered $\left(30^{\circ}\right)$.

\section{Acknowledgments}

The authors would like to acknowledge the invaluable support provided by the 14- by 22Foot Subsonic Tunnel team and by their colleagues in the Aeroacoustics and Advanced Sensing \& Optical Measurement branches who contributed to the realization and completion of the N2AEXTE HWB aeroacoustic test. This work was funded by the NASA Environmentally Responsible Aviation Project.

\section{$\underline{\text { References }}$}

1. Collier, F., "Environmentally Responsible Aviation (ERA) Project", presentation given at the NASA Fundamental Aeronautics Program, Third Annual Meeting, Atlanta, GA, Sept. 29Oct. 1, 2009.

2. Kawai, R. T. "Acoustic Prediction Methodology and Test Validation for an Efficient LowNoise Hybrid Wing Body Subsonic Transport", Final report for NASA Contract Number NNL07AA54C, Feb. 2011.

3. Brooks, T. F., "Aeroacoustic Scaling Principles and the Hybrid Wing Body Test", Keynote Address, 17 ${ }^{\text {th }}$ AIAA/CEAS Aeroacoustics Conference, Portland, OR, June 6-8, 2011.

4. Hutcheson, F.V., "Overview of the NASA Hybrid Wing Body Aeroacoustic Test", AIAA presentation at the $20^{\text {th }}$ Aeroacoustics Conference in Atlanta, GA (June 2014). 
5. Heath, S. L., Brooks, T. F., Hutcheson, F. V., Doty, M. J., Bahr, C. J., Hoad, D., Becker, L., Humphreys, W. M., Burley, C. L., Stead, D. J., Pope, D. S., Spalt, T. B., Kuchta, D., Plassman, G., Moen, J., "NASA Hybrid Wing Body Aircraft Aeroacoustic Test Data Report", NASA TM, 2014 (to be published).

6. Heath, S. L., Brooks, T. F., Hutcheson, F. V., Doty, M. J., Haskin, H. H., Spalt, T. B., Bahr, C. J., Burley, C. L., Bartram, S. M., Humphreys, W. M., Lunsford, C. B., Popernack, T., Colbert, S., Hoad, D., Becker, L., Stead, D., Kuchta, D., Yeh, L., "Hybrid Wing Body Aircraft Acoustic Test Preparations and Facility Upgrades", AIAA paper 2013-2623, $28^{\text {th }}$ AIAA Aerodynamic Measurement Technology, Ground Testing, and Flight Testing Conference, June 2013, San Diego, CA.

7. Doty, M. J., Brooks, T. F., Burley, C. L., Bahr, C. J., Pope, D. S., "Jet Noise Shielding Provided by a Hybrid Wing Body Aircraft", AIAA paper accepted for submission at the $20^{\text {th }}$ AIAA/CEAS Aeroacoustics Conference in Atlanta, GA, June 16-20, 2014.

8. Burley, C. L., Brooks, T. F., Hutcheson, F. V., Doty, M. J., Lopes, L. V., and Pope, D. S., "Noise Scaling and Community Noise Metrics for the Hybrid Wing Body Aircraft", AIAA paper accepted for submission at the $20^{\text {th }}$ AIAA/CEAS Aeroacoustics Conference in Atlanta, GA, June 16-20, 2014.

9. Bahr, C. J., Brooks, T. F., Humphreys, W. M., Spalt, T. B., Stead, D. J., "Acoustics Data Processing and Transient Signal Analysis for the Hybrid Wing Body 14- by 22-foot Subsonic Wind Tunnel Test", AIAA paper accepted for submission at the $20^{\text {th }}$ AIAA/CEAS Aeroacoustics Conference in Atlanta, GA, June 16-20, 2014.

10. Spalt, T. B., Brooks, T. F., Bahr, C. J., Plassman, G. E., Becker, L. E., and Stead, D. J., "Calibration of the LaRC's 14- by 22-Foot Subsonic Wind Tunnel in Acoustic Configuration", AIAA paper accepted for submission at the $20^{\text {th }}$ AIAA/CEAS Aeroacoustics Conference in Atlanta, GA, June 16-20, 2014.

11. Humphreys, W. M., Brooks, T. F., Bahr, C. J., Spalt, T. B., Bartram, S. M., Culliton, W. G., Becker, L. E., "Development of a Microphone Phased Array Capability for the 14- 22-Foot Subsonic Tunnel", AIAA paper accepted for submission at the $20^{\text {th }}$ AIAA/CEAS Aeroacoustics Conference in Atlanta, GA, June 16-20, 2014.

12. Sutliff, D. L. and Walker, B. E., "Shielding Characteristics using an Ultrasonic Configurable Artificial Noise Source to Generate Modes - Experimental Measurements and Analytical Predictions," AIAA paper accepted for submission at the $20^{\text {th }}$ AIAA/CEAS Aeroacoustics Conference in Atlanta, GA, June 16-20, 2014.

13. Keller, J. B., "Geometrical Theory of Diffraction", Journal Opt. Soc. America, vol 52, pp. 116-130, 1962.

14. Redferan, S. W., "Some Acoustical Source-Observer Problems", Phil. Mag., ser. 7, vol.30, pp. 223-236, 1940.

15. Beranek, L. L., "Noise and Vibration Control”, McGraw-Hill, Inc., 1971. 
16. Brooks, T. F., Humphreys, W. M., "Effect of Directional Array Size on the Measurement of Airframe Noise components", AIAA paper 99-1958, $5^{\text {th }}$ AIAA/CEAS Aeroacoustics Conference, Bellevue, WA, May 1999. 